\title{
Malignant GOO: Are duodenal stenting and surgical gastrojejunostomy obsolete?
}

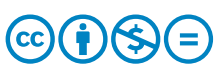

\author{
Authors \\ Margaret G. Keane, Mouen A. Khashab \\ Institution \\ Johns Hopkins Hospital, Department of Gastroenterology \\ and Hepatology, Baltimore, Maryland, United States \\ Bibliography \\ Endoscopy International Open 2020; 08: E1455-E1457 \\ DOI 10.1055/a-1231-5011 \\ ISSN 2364-3722 \\ (c) 2020. The Author(s).
}

\begin{abstract}
This is an open access article published by Thieme under the terms of the Creative Commons Attribution-NonDerivative-NonCommercial License, permitting copying and reproduction so long as the original work is given appropriate credit. Contents may not be used for commecial purposes, or adapted, remixed, transformed or built upon. (https://creativecommons.org/licenses/by-nc-nd/4.0/)
\end{abstract}

\section{Corresponding author}

Mouen A. Khashab, MD, Associate Professor of Medicine, Division of Gastroenterology and Hepatology, Johns Hopkins Hospital, 1800 Orleans Street, Zayed Bldg, Suite 7125B, Baltimore, MD 21287, United States

Fax: +443-683-8335

mkhasha1@jhmi.edu
Endoscopic ultrasound-guided gastroenterostomy (EUS-GE) has important advantages over surgical gastroenterostomy and enteral stent (ES) placement in the management of gastric outlet obstruction (GOO). Traditionally, surgical gastrojejunostomy was used to treat GOO, but this approach is limited by its associated morbidity in an often palliative population [1-4]. ES offers a minimally invasive alternative, which has good shortterm outcomes. However, in the longer term, ES is associated with recurrent obstruction, often necessitating reintervention [4-8].

We reported the first US clinical experience with EUS-GE in 2013. Since then, there have been several multicenter studies that have shown that compared with surgery, EUS-GE has similar rates of clinical success ( $90 \%$ in surgical GE vs $87 \%$ in EUS$G E, P=.18$ ) and adverse events ( $16 \%$ in surgical GE vs $25 \%$ in EUS-GE, $P=.3$ ) [9]. When compared with duodenal stenting, clinical success was similar but recurrent symptoms and rates of reintervention were lower in the EUS-GE group [10].

In this issue of the journal, Kastelijn and colleagues report on a multicenter retrospective study that combined EUS-GE cases from seven centers in four European countries [11]. The primary aim of this study was to assess the rate of EUS-GE stent occlusion over time. In 45 patients with malignant GOO, recurrent obstruction occurred in only $6.1 \%$ of cases. This low rate is similar to rates reported in previous studies, which ranged from $0 \%$ to $14 \%[9,10,12-15]$. The median follow-up time in this study was relatively short at 59 days. Our group has recently reported on the durability of EUS-GE with the longest follow-up to date. In malignant GOO, we also found low rates of recurrent lumen-apposing metal stent (LAMS) occlusion at $4 \%$, during a median follow-up of 196 days [15].

In the study by Kastelijn et al., technical and clinical success rates were $86.7 \%$ and $73.3 \%$, respectively [11]. This was at the lower end of rates reported in previous studies, in which technical success ranged from $86.7 \%$ to $100 \%$ and clinical success from $83.3 \%$ to $95.8 \%[9,10,12-17]$. The authors suggested this could be because endoscopists included their early EUSGE cases. In this study, $35.7 \%$ of patients had ascites and $33.3 \%$ had peritoneal carcinomatosis. The technical success rate was lower in patients with ascites (73.3\% vs $92.6 \%$ ) and peritoneal carcinomatosis ( $76.9 \%$ vs $92.3 \%$ ). Although a small amount of ascites does not preclude EUS-GE, we generally prefer to place a duodenal stent in patients with large-volume ascites or known extensive peritoneal adhesions because of the increased risk of secondary peritonitis, leakage, and dehiscence.

The rate of adverse events (AEs) (26.7\%) in this study was substantially higher than rates reported previously, which ranged from $3.5 \%$ to $20.8 \%[9,10,13-17]$. All fatal AEs and most of the stent misplacement occurred at one center, soon after introduction of the procedure. The rate of fatal AEs in this study was also striking at $11.1 \%$ (5 patients). Interestingly, the rate of stent misplacement (17.8\%) in this study was similar to that reported by previous studies, occurring in $7 \%$ to $36 \%$ of cases $[9,10,13-17]$. What may have been different in this study was that endoscopic rescue only appeared to be feasible in around half of the cases. Fatal peritonitis and abdominal sepsis, therefore, developed in $8.9 \%$ of patients. 
Although stent misplacement is often a feared complication, we and others have described how it can be successfully managed endoscopically. The most common misdeployment scenario is when the distal flange is misdeployed outside of the jejunum. The stent can simply be removed and the gastric defect closed with endoscopic clips (e.g. over-the-scope clip), also allowing completion of the procedure with placement of a further LAMS or duodenal stent at the same time. Longer-term complications, such as a buried stent, can be remedied by cannulating the track and placing a second LAMS within the existing stent [18]. Importantly, the gastroenterostomy fistula is thought to take several weeks to mature, especially in malnourished patients. In this study, the authors describe a case where one patient underwent jejunoscopy through the LAMS 13 days after the initial EUS-GE, which led to stent dislocation necessitating surgical repair. Interventions through the EUS-GE, therefore, should be avoided until the fistula track has fully formed.

The final fatality in this study was from delayed intraperitoneal bleeding following a technically successful procedure. Post-procedure bleeding has been reported following EUS-GE for various reason [19]. Patients with pancreaticobiliary malignancy have a high incidence of portal vein thrombosis and therefore perigastric varices, which can be potentially compromised by placement of an EUS-GE stent. Doppler of the track is an important step prior to LAMS insertion to ensure there are no intervening vessels; however, this can underestimate the presence of perigastric varices as they can be easily compressed by the tip of the echoendoscope. Another cause of bleeding after EUS-GE is often attributed to balloon dilation of the LAMS. Rapid expansion of the stent lumen is thought to possibly cause sheering of adjacent vessels. Dilation immediately after stent placement was performed in $30.8 \%$ of cases in this study. In our experience, we have found that dilation of the stent is not an essential step and we would advocate simply allowing the stent to naturally expand over 24 hours.

Even in the hands of experienced interventional endoscopists, there is undoubtedly a learning curve for advanced EUS procedures. For EUS-guided biliary drainage, around 30 to 40 cases are needed to achieve proficiency and more to achieve true mastery of the technique $[20,21]$. We have recently looked at the learning curve for EUS-GE using cumulative sum analysis and have found that around 25 cases are needed to achieve proficiency and 40 cases to achieve mastery [22].

To date, a number of different methods of performing EUSGE have been described [23]. The most commonly used methods in North America and Europe are balloon-assisted GE and direct GE. A key difference between these techniques is that in the balloon-assisted approach, after the inflated balloon has been punctured with a $19 \mathrm{G}$ needle to obtain jejunal access, a wire is advanced into the jejunum and the LAMS placed over the wire. In the direct approach, after the small bowel has been filled with contrast and methylene blue, it is then directly punctured with a LAMS with an electrocautery-enhanced delivery system. Many endoscopists, especially when starting to perform EUS-GE, intuitively feel that placing a LAMS over a wire is safer. Comparative studies have found that in expert hands, both techniques have high rates of technical and clinical suc- cess, but shorter procedure times are seen with the direct method (mean 35.7 minutes versus 89.9 minutes, $\mathrm{P}<.001$ ) [14]. The authors in this study acknowledged that all fatal AEs and most stent misplacement occurred at one center, using the balloon-assisted approach soon after the procedure was introduced. In our experience, the step of placing a wire across the GE fistula before stent placement can, in fact, push the jejunum away from the stomach, potentially leading to stent misplacement and technical failure. Therefore, we favor the direct method and advise against wire advancement prior to stent placement.

The authors concluded that duodenal stent placement carries less risk and should remain the preferred treatment in most patients with GOO with short life expectancy. However, with better chemotherapy and radiation therapy, the life expectancy of many patients with malignant GOO is now increasing. For example, $10 \%$ of patients diagnosed with pancreatic cancer in the United States will now live more than 5 years [24]. If managed by ES, occlusion and need for reintervention would be expected in a growing number of patients, making this option increasingly problematic [24]. Surgical gastrojejunostomy provides good long-term results but its associated morbidity and longer recovery limits its utility [9]. EUS-GE, therefore, is an attractive option for management of malignant GOO. In experienced hands, EUS-GE is a safe technique with good durability in management of malignant GOO. Nonetheless, EUS-GE is technically challenging and its wide dissemination remains questionable. Randomized studies evaluating use of EUS-GE will likely lead to its wider acceptance.

\section{Competing interests}

Dr. Khashab is a consultant and on the advisory board for Boston Scientific an Olympus America and a consultant for Medtronic

References

[1] Mintziras I, Miligkos M, Wachter S et al. Palliative surgical bypass is superior to palliative endoscopic stenting in patients with malignant gastric outlet obstruction: systematic review and meta-analysis. Surg Endosc 2019; 33: 3153-3164

[2] Minata MK, Bernardo WM, Rocha RS et al. Stents and surgical interventions in the palliation of gastric outlet obstruction: a systematic review. Endosc Int Open 2016; 4: E1158-E1170

[3] Jang S, Stevens T, Lopez R et al. Superiority of gastrojejunostomy over endoscopic stenting for palliation of malignant gastric outlet obstruction. Clin Gastroenterol Hepatol 2019; 17: 1295-302 e1

[4] Jeurnink SM, Steyerberg EW, van Hooft JE et al. Surgical gastrojejunostomy or endoscopic stent placement for the palliation of malignant gastric outlet obstruction (SUSTENT study): a multicenter randomized trial. Gastrointest Endosc 2010; 71: 490-499

[5] Upchurch E, Ragusa M, Cirocchi R. Stent placement versus surgical palliation for adults with malignant gastric outlet obstruction. Cochrane Database System Rev 2018; 5: CD012506

[6] Khashab M, Alawad AS, Shin EJ et al. Enteral stenting versus gastrojejunostomy for palliation of malignant gastric outlet obstruction. Surg Endosc 2013; 27: 2068-2075 
[7] Maetani I, Tada T, Ukita T et al. Comparison of duodenal stent placement with surgical gastrojejunostomy for palliation in patients with duodenal obstructions caused by pancreaticobiliary malignancies. Endoscopy 2004; 36: 73-78

[8] Uemura S, Iwashita T, Iwata K et al. Endoscopic duodenal stent versus surgical gastrojejunostomy for gastric outlet obstruction in patients with advanced pancreatic cancer. Pancreatology 2018: doi:10.1016/j. pan.2018.04.015

[9] Khashab MA, Bukhari M, Baron TH et al. International multicenter comparative trial of endoscopic ultrasonography-guided gastroenterostomy versus surgical gastrojejunostomy for the treatment of malignant gastric outlet obstruction. Endosc Int Open 2017; 5: E275E281

[10] Chen YI, Itoi T, Baron TH et al. EUS-guided gastroenterostomy is comparable to enteral stenting with fewer re-interventions in malignant gastric outlet obstruction. Surg Endosc 2017; 31: 2946-2952

[11] Kastelijn JB, Moons LMG, Garcia-Alonso FJ et al. Patency of endoscopic ultrasound-guided gastroenterostomy in the treatment of malignant gastric outlet obstruction. Endosc Int Open 2020; 08: E1194-E1201

[12] Khashab MA, Kumbhari V, Grimm IS et al. EUS-guided gastroenterostomy: the first US. clinical experience (with video). Gastrointest Endosc 2015; 82: 932-938

[13] Perez-Miranda M, Tyberg A, Poletto D et al. EUS-guided gastrojejunostomy versus laparoscopic gastrojejunostomy: an international collaborative study. J Clin Gastroenterology 2017; 51: 896-899

[14] Chen YI, Kunda R, Storm AC et al. EUS-guided gastroenterostomy: a multicenter study comparing the direct and balloon-assisted techniques. Gastrointest Endosc 2018; 87: 1215-1221

[15] Kerdsirichairat T, Irani S, Yang J et al. Durability and long-term outcomes of direct EUS-guided gastroenterostomy using lumen-apposing metal stents for gastric outlet obstruction. Endosc Int Open 2019; 7: E144-E150
[16] Ge PS, Young JY, Dong W et al. EUS-guided gastroenterostomy versus enteral stent placement for palliation of malignant gastric outlet obstruction. Surg Endosc 2019; 33: 3404-3411

[17] Tyberg A, Perez-Miranda M, Sanchez-Ocana R et al. Endoscopic ultrasound-guided gastrojejunostomy with a lumen-apposing metal stent: a multicenter, international experience. Endosc Int Open 2016; 4: E276-E281

[18] Ligresti D, Amata M, Barresi L et al. The lumen-apposing metal stent (LAMS)-in-LAMS technique as an intraprocedural rescue treatment during endoscopic ultrasound-guided gastroenterostomy. Endoscopy 2019; 51: E331-E332

[19] Chavan R, Ramchandani M, Nabi Z et al. Luminal and extraluminal bleeding during EUS-guided double-balloon-occluded gastrojejunostomy bypass in benign gastric outlet obstruction with portal hypertension. VideoGIE 2020; 5: 64-67

[20] James TW, Baron TH. Practical applications and learning curve for EUS-guided hepaticoenterostomy: results of a large single-center US retrospective analysis. Endosc Int Open 2019; 7: E600-E607

[21] Oh D, Park DH, Song T] et al. Optimal biliary access point and learning curve for endoscopic ultrasound-guided hepaticogastrostomy with transmural stenting. Therap Adv Gastroenterol 2017; 10: 42-53

[22] Jovani M, Ichkhanian Y, Parsa N et al. Su1277 How many EUS-guided gastrojejunostomy procedures are necessary for proficiency? an appraisal of the learning curve for a single operator. GIE 2020; 91 : AB307-AB308

[23] Irani S, Baron TH, Itoi T et al. Endoscopic gastroenterostomy: techniques and review. Curr Opin Gastroenterol 2017; 33: 320-329

[24] Howlader N, Noone AM, Krapcho M et al. SEER Cancer Statistics Review. 1975-2017. Available at: https://seer.cancer.gov/csr/ 1975_2017| 